Research Paper:

\title{
Comparing of Symptoms, Defense Mechanisms and Coping Styles in Women and Men With Borderline Personality Disorder
}

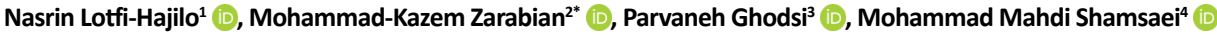 \\ 1. Department of Psychology, Faculty of Humanities, Electronic Tehran Branch, Islamic Azad University, Tehran, Iran. \\ 2. Behavioral Disorder and Substance Abuse Research Center, Hamadan University of Medical Sciences, Hamadan, Iran. \\ 3. Department of Psychology, Faculty of Psychology and Social Sciences, Central Tehran Branch, Islamic Azad University, Tehran, Iran \\ 4. Spiritual Health Research Center, Iran University of Medical Sciences, Tehran, Iran.
}

\begin{tabular}{|c|c|}
\hline $\begin{array}{l}\text { Use your device to scan } \\
\text { and read the article online }\end{array}$ & Citation Lotfi-Hajilo N, Zarabian MK, Ghodsi P, Shamsaei MM. Comparing of Symptoms, Defense Mechanisms and Coping \\
\hline 口ing & $\begin{array}{l}\text { Styles in Women and Men With Borderline Personality Disorder. Avicenna J of Neuropsychophysiology. 2017; 4(3):113-121. } \\
\text { http://dx.doi.org/10.32598/ajnpp.4.3.113 }\end{array}$ \\
\hline 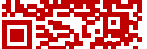 & doi http://dx.doi.org/10.32598/ajnpp.4.3.113 \\
\hline
\end{tabular}

\section{(c) (1) (\$)}

Article info:

Received: 27 Dec 2016

Accepted: 10 May 2017

Available Online: 01 Aug 2017

Keywords:

Symptom assessment, Defense mechanisms, Coping style, Borderline Personality Disorder (BPD)

\section{A B STRACT}

Background: Borderline Personality Disorder (BPD) is the most common personality disorder in psychiatric settings but it still presents with some ambiguities in its symptoms, etiology, individual, and social consequences.

Objectives: The purpose of this study was to compare the severity of BPD symptoms, defense mechanisms, and coping styles among men and women with this disorder.

Materials and Methods: This is a cross-sectional study with two study groups conducted in Hamadan Province from March 2018 to June 2018. The simple random sampling method was used to select the study subjects. The sample included 27 men and 27 women with BPD who were referred to the offices of 3 psychiatrists during the study time. The study variables included the severity of Borderline Personality Disorder symptoms assessed based on Borderline Personality Disorder Severity Index (BPDSI) and mature, immature and neurotic defense mechanisms assessed based on the Defense Style Questionnaire (DSQ-40) and coping styles of emotional, problem and avoidancefocused assessed based on the Coping Inventory for Stressful Situations (CISS) questionnaire among women and men with this disorder. The obtained data were analyzed by descriptive statistics and t-test for independent groups and Mann-Whitney U test in SPSS V. 24.

Results: The results indicate that the severity of BPD in male patients is significantly more than women $(U=199, P<0.05)$ and men significantly use the immature $(t=4.88, P<0.05)$ and neurotic defense mechanisms more than female patients $(U=58, P<0.05)$, but the mature defense mechanisms less than women $(t=-5.54, P<0.05)$. Male patients also significantly use more the emotional-focused $(t=6.73, P<0.05)$ and the avoidance-focused coping styles $(U=125, P<0.05)$, but less the problem-focused coping style compared to female patients $(\mathrm{t}=-3.47, \mathrm{P}<0.05)$.

Conclusion: While, the prevalence of this disorder is more reported in women, the severity of symptoms, and use of immature and neurotic defense mechanisms and emotional and avoidantfocused coping style in men is more than those in women suffering from this disorder. The reason for this finding should be investigated in future research.

\section{* Corresponding Author:}

Mohammad-Kazem Zarabian, PhD.

Address: Behavioral Disorder and Substance Abuse Research Center, Hamadan University of Medical Sciences, Hamadan, Iran.

E-mail: h93zarabian@gmail.com 


\section{Introduction}

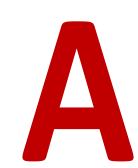

mong personality disorders, Borderline Personality Disorder (BPD) is one of the most common and important disorders that consumes a significant amount of mental health resources (more than 40\%) [1]. An unstable and stressful pattern of interpersonal relationships characterized by fluctuation between idealization and valuedeformation, self-concept instability, impulsive behavior, threats, gestures, or repeated suicide or self-harm behaviors, emotional instability, intense and disproportionate anger, paranoid thinking, and dissociative patterns related to stress are observed in this disorder [2].

It is actually the most common psychiatric disorder in psychiatric treatment settings [3]. Its prevalence in the general population ranges from $1.6 \%$ to $5.9 \%$, in primary care settings is about $6 \%$, in mental health clinics is $10 \%$, and in clinical environments is approximately $20 \%$. About $75 \%$ of the cases are women [4]. Suicide attempts occur in $84 \%$ of these patients [5] and about $80 \%$ of them committed self-mutilation once in their life and $55 \%$ to $85 \%$ of borderline patients, who harmed themselves, reported at least one suicide attempt [6]. Defensive mechanisms are automated psychological responses to protect an individual from anxiety [7]. Coping styles can be considered as a set of functions that can help a person tolerate, avoid, or minimize stress [8].

Preventive science tries to strengthen humans' ability through using coping styles and effective defense mechanisms as a spell against mental disorders [9]. In the psychodynamic theory, defense mechanisms play an important role in the mental health so that any mental disorder is associated with some inadequate defensive mechanisms [10]. Freud also considered the frequency of using different defense mechanisms as the main predictor for recognizing personality, psychopathology, and adjustment [11].

The symptoms of BPD are associated with inappropriate defense mechanisms and ineffective coping styles [12]. The relationship between defense mechanisms and psychiatric disorders has been already reported and confirmed [13] as well as the relationship between defense mechanisms and BPD [14-16]. The studies also indicate that personality factors and coping styles are directly and indirectly involved in the creation and continuation of various types of disorders [17-19]. It seems that the use of maladaptive coping styles is the cause of psychological pressure in persons with personality disorder [20].

The relationship between personality disorder, psychological stress, and ineffective coping styles has been already proven [21]. Although the relationship between personality disorders and maladaptive coping styles has been already proven, our knowledge on this relationship and its affective variables are limited [20]. Studies also show that people with BPD are very sensitive to environmental conditions and stressors, and this is one of the important factors that comprise a wide range of symptoms among them [22]. For example, emotional disturbances, which are the core of BPD and related to emotional regulation mechanisms, are due to their emotional coping style [23].

Scientific resources lack enough information about the influential variables on BPD [24] and more research is needed in this regard [25]. Personality disorders present with the most chronic symptoms of psychopathology and lack effective therapy. There are still a number of ambiguities in the field of symptoms, etiology, and the individual and social consequences of this disorder. Although it is more prevalent in women, the results of studies show that variables such as gender interfere with the symptoms of BPD [26].

The prevalence of women with BPD was reported to be $75 \%$ [4], but this number seems unreliable because of the sampling and diagnostic bias or biological or sociocultural differences between men and women that lead to a higher diagnosis of BPD in women. For example, if women seek help for their psychological problems three times more than men then it is not surprising that the disorder is identified in women three times as much as in men. If the higher prevalence of this disorder is true in women, this might be due to biological factors such as gender and socio-cultural factors. For example, the characteristics of the psychological neurotic personality that are thought to be related to the disorder and are influenced by biological factors occur more often in women or abused sexuality victims. Thus the commonest cause of the disorder is 10 times more in women than men.

The most popular idea about gender differences in the disorder is that women are more emotional than men so more prone to this disorder. Although various factors such as premenstrual stress, postpartum depression, menstruation, and even the use of contraceptive pills have been suggested for psychological state of BPD in 
the sexes, these factors are clumsy to explain this gender differences prevalence.

Because research has focused more on women with this disorder and studies have pointed several factors involved in the relationship between gender and personality disorder, the main question in this research is that what the differences are between the symptoms, defense mechanisms and coping styles of women and men with the BPD. The results of this study can be used to recognize the effect of gender variable in the symptoms, coping styles, and defense mechanisms as important variables affecting psychopathology. This study, therefore, aimed to compare the severity of BPD symptoms, defense mechanisms (mature, immature, and neurotic), and coping styles (emotional, problem and avoidance-focused) among women and men with BPD.

\section{Materials and Methods}

This study was a cross-sectional with two groups (women and men). The study variables included the severity of BPD symptoms assessed by the Borderline Personality Disorder Severity Index (BPDSI). This index was introduced by Weaver and Clus in 1993.

In Iran, the $85 \%$ reliability so acceptable validity has been reported. The other study variables were mature, immature, and neurotic defense mechanisms assessed by the Defense Style Questionnaire (DSQ)-40. For the Defense Style Questionnaire (DSQ)-40, the Cronbach alpha values for mature, immature and neurotic styles were found as $75 \%, 73 \%$, and $74 \%$, respectively which were in the range of acceptable validity. The final variables were coping styles of the emotional-, problem-, and avoidance-focused assessed by the Coping Inventory for Stressful Situations (CISS) questionnaire that its Cronbach alpha values were $92 \%$ for problem-focused, $82 \%$ for emotional-focused, and $85 \%$ for avoidance-focused. So, it has acceptable validity. The simple random sampling method was used to select the target study subjects ( 27 women and 27 men).
The criteria for entering the research were diagnosis of BPD based on the diagnostic criteria of this disorder in DSM- 5 by a psychiatrist, having minimum degree of diploma education, aged between 20 and 35 years, not all the criteria used to diagnose other psychiatric disorders are based on DSM-5 by a psychiatrist, without physical illnesses, and resident in the city of Hamadan. The exclusion criteria were refusal of the patients to continue the study for any reason. The research data were extracted from the questionnaires and analyzed by descriptive statistics and t-test for independent samples and MannWhitney U test in SPSS V. 24. In order to observe the research ethical principles, all subjects signed the written consent form of participating in the research.

\section{Results}

The Mean $\pm S D$ age of the subjects was $25.70 \pm 1.32$ for men and was $25.78 \pm 1.19$ years for women. In both groups, most subjects had a high school diploma or higher. The Kolmogorov-Smirnov test was used to examine the normal distribution of all study variables. The results showed that the significance level of the $z$ in Kolmogorov-Smirnov test was greater than 0.05 ( $P>0.05)$, except avoidance-focused coping style in men and severity of the disorder and neurotic defensive mechanisms in women. The results of the Mann-Whitney $U$ test (because of the non-normal distribution of the severity of symptoms in the women's group) showed that the severity of BPD scores was significantly higher in men than women $(U=199, \mathrm{P}<0.05)$ (Table 1).

The Independent samples t-test was used to examine the significant difference in the mean values of the immature and mature defense mechanisms between male and female patients (because of the natural distribution of scores). The results showed that homogeneity assumption of variances for mature defense mechanisms was significant $(f=3.30, d f 1=52, d f 2=45.03, P<0.075$ ) but not established for immature defense mechanism $(f=10.90, d f 1=52, d f 2=41.78, P<0.002)$, therefore the replacement $t$ value was used.

Table 1. The Mann-Whitney $U$ test results of the two groups

\begin{tabular}{cccccc}
\hline Variable & Mann-Whitney U & Mean Rank of Men & Mean Rank of Women & z & Sig. \\
\hline Severity of symptoms & 199 & 33.63 & 21.37 & -2.88 & 0.004 \\
Neurotic defense mechanisms & 58 & 38.85 & 16.15 & -5.31 & 0.000 \\
Avoidance-focused & 125 & 36.35 & 18.65 & -4.17 & 0.000 \\
\hline
\end{tabular}


Table 2. The t-test results between the two groups' means

\begin{tabular}{|c|c|c|c|c|c|c|c|}
\hline Variable & df & $\begin{array}{l}\text { Mean of } \\
\text { Men }\end{array}$ & $\begin{array}{l}\text { Mean of } \\
\text { Women }\end{array}$ & $\begin{array}{l}\text { Difference of } \\
\text { Means }\end{array}$ & SD & $\mathbf{t}$ & Sig. \\
\hline $\begin{array}{c}\text { Immature } \\
\text { defense mechanisms }\end{array}$ & 41.78 & 175.26 & 185.04 & 17.22 & 3.53 & 4.88 & 0.000 \\
\hline $\begin{array}{l}\text { Mature defense } \\
\text { mechanisms }\end{array}$ & 52 & 25 & 29.37 & -4.37 & 0.79 & -5.54 & 0.000 \\
\hline Emotional-focused & 32.98 & 63.45 & 48.19 & 15.26 & 2.27 & 6.73 & 0.000 \\
\hline Problem-focused & 44.22 & 31.70 & 36 & -4.30 & 1.24 & -3.47 & 0.001 \\
\hline
\end{tabular}

AJNPP

Table 2 presents that $t$ values calculated between two groups in immature defense mechanisms ( $t=4.88$, $\mathrm{P}<0.05)$, and between two groups regarding mature defense mechanisms ( $t=-5.54, P<0.05)$ are significant at the level of 0.05 and according to observed means of men values, they have less mature defense mechanisms than women. In order to investigate the significant differences in the scores of neurotic defense mechanisms between men and women, the Mann-Whitney $U$ test (because of the non-normal distribution of the scales of neurotic defense mechanism in the female group) was used. The results of the Mann-Whitney $U$ test showed that the scores of neurotic defense mechanisms in men were significantly higher than women $(\mathrm{U}=58, \mathrm{P}<0.05)$ (Table 1).

In order to investigate the significant difference between the emotional and problem-focused coping styles between two groups (which have normal distribution), the homogeneity assumptions of variances were studied (emotional-focused; $f=29.13$, df1 $=52$, $\mathrm{df}^{2}=32.98, \mathrm{P}<0.000$ ) (problem-focused; $\mathrm{f}=11.41$, $\mathrm{df} 1=52$, $\mathrm{df2}=44.22, \mathrm{P}<0.001)$. Because the homogeneity assumption of the variances was not accepted, therefore the replacement $t$ value was used.

Table 2 shows that the calculated $t$ value of the two groups in the emotional-focused coping style ( $t=6.73$, $\mathrm{P}<0.05)$ and also between two groups in problem-focused coping style $(t=-3.47, P<0.05)$ at the level of 0.05 is significant. According to means observed, the emotionalfocused coping style is seen more in men and problemfocused coping style is seen less in women.In order to study the significant difference in avoidance-focused coping style scores between men and women, the MannWhitney $U$ test (because of the non-normal distribution of avoidance focus coping style scores) was used. The results of the Mann-Whitney $U$ test showed that avoidant- focused coping style of men was significantly higher than women's scores $(\mathrm{U}=125, \mathrm{P}<0.05)$ (Table 1$)$.

\section{Discussion}

The first hypothesis of the research (there is a difference between the severity of symptoms in women and men with Borderline Personality Disorder) was confirmed. The results show that the severity of symptoms in men was significantly higher than women. Studies have only been conducted to compare the prevalence of the disorder in both sexes. Based on the theoretical background of this disorder, including Linehan's (1993) viewpoint, the symptoms of BPD reflect an unstable behavioral pattern as well as attempts to injure, harm, or kill themselves, with experiencing emotional, cognitive, and interpersonal dysregulation [27]. Therefore it seems that these conditions are likely to occur in men more than women and cause more symptoms.

The second hypothesis of the research (there is a difference between the mechanisms of defense in women and men with the BPD) was confirmed, too. Because women use mature defensive mechanisms more than men they feel a healthier mental status, too. The research has shown that physical and psychological health of the individuals are closely related to their defense mechanisms [28-33]. This association was also found, reported, and approved in the studies conducted on the relationship between defense mechanisms and psychiatric disorders [13] as well as ineffective defense mechanisms and BPD [15-16]. Women's supremacy in using mature defense mechanisms and having less severity of symptoms compared to the men is consistent with the results of studies that reported physical health and positive performance and psychological and social adjustment are consequences of using mature defense mechanisms [33, 34]. 
The third hypothesis of the research (there is a difference between the coping styles in women and men with BPD) was confirmed, too. Men compared to women use more frequently the emotional-focused and avoidancefocused coping styles. In numerous research studies, the correlation between coping styles and other psychological variables such as suicide, identity crisis, emotional intelligence, failure, and disorders such as depression, anxiety, and sexual differences was studied [19-22, 3541]. But no research was found that compared the coping styles in men and women with BPD.

The results of this study showed that men use emotional-focused coping style significantly more than women. Based on the theoretical background of the research, the reason for this difference relates to the nature of BPD which is an impairment in emotional regulation. Therefore, because men may have fewer emotionally selfregulating skills than women, this condition is likely to be stronger in women than men with this disorder. The use of more problem-focused coping style in men may also be due to the fact that a problem solving that involves more than three processes involves: 1 . Understanding the issues; and 2. Compiling and analyzing various and possible solutions; and 3.Implementation of solutions in women with this disorder are stronger than men and it seems that women with this disorder have better management of distress and control of arousal and stress and Because of this point problem-focused coping style in them is better. Using more avoidant-focused coping style by men with this disorder indicates that women are more skilled in applying the exposure method.

What was said can be seen as an explanation of why the severity of symptoms in men with the BPD is more than women. Men with BPD may less trained in interpersonal skills and perhaps this is why the dominant approaches in the treatment of personality disorder are a focus in training interpersonal skills and getting the sense of efficiency in the interpersonal relationship [42]. This explanation is consistent with Levy's study [43] that reported impulsivity, emotional instability, and selfdestructive behaviors (often due to conceptual or real problems in interpersonal relationships) were higher in men with BPD [43]. On the other hand, an overview of the theoretical background of the research showed that when emotional information is not properly received and evaluated through cognitive processing, it is interpreted as helplessness and harm and this distress can, in turn, aggravate person's cognition and emotion disturbances and increase the possibility of using neurotic and immature mechanisms under stressful conditions [32].
The above findings are consistent with the results of this study that more men with this disorder use immature and neurotic defensive mechanisms and emotional focus coping style. Also, the results of this study show that men use less problem-focused coping style and use more immature and neurotic defense mechanisms. These findings agree with Andrews et al. (1993) results who reported that the neurotic and immature defense mechanisms are the methods of inappropriate and ineffective exposure [44], the same notion of not using the problem-focused coping style. In addition, the findings of the study on using immature and neurotic defenses and emotional-focused coping style in men are consistent with studies that reported the impairment of defense mechanisms can be defects in identifying and expressions of emotions $[30,31]$, the same as the use of the emotional-focused coping style.

\section{Conclusion}

The severity of BPD in men is significantly more than that of women. Men use the immature and neurotic mechanisms significantly more than women. Men also use more emotional- and avoidance-focused coping styles. The research findings can be generalized to those patients who refer to the psychiatrist's offices but cannot be extended to the hospitalized patients. In addition, because the current study was only carried out by referring to three offices, this generalizability becomes even more limited. Because of the heterogeneity of the patients and the impossibility of their match, this factor can also be considered a limitation for research findings. Small sample size further limits the generalizability of the study findings.

We suggest that the same study be conducted on the patients admitted to the hospitals and the results were compared with non-admitted patients. The variables of this study in borderline patients with other mental disorders can be compared, too. In addition, to evaluate the efficacy of the treatment methods, it is suggested that the variables of this study be compared before and after the application of therapeutic methods. Also, the effectiveness of different therapeutic methods in the variables of this study be compared with each other. In similar studies, larger sample size should be used if possible. The relationship between the variables of this research can also be investigated by correlation methods.

\section{Ethical Considerations}

\section{Compliance with ethical guidelines}

All the participants were given information about the goal of the study. They were aware that taking part in this 
study was voluntary and had the right to refuse participation or leave the study whenever they wish.

\section{Funding}

The present paper was extracted from the MSc. thesis of the first author, Department of Psychology, Faculty of Humanities, Electronic Tehran Branch, Islamic Azad University, Tehran, Iran.

\section{Authors contributions}

All authors contributed in preparing this article.

\section{Conflict of interest}

The authors declared no conflict of interest.

\section{References}

[1] Oldham J. Borderline Personality Disorder and suicidality. American Journal of Psychiatry. 2006; 163(1):20-6. [DOI:10.1176/appi. ajp.163.1.20] [PMID]

[2] Khosravi Z, Rahmatinejad P. [The relationship between Borderline Personality Disorder and bipolar disorder type II based on Borderline Personality Organization (Persian)]. Journal of Clinical Psychology. 2014; 8(32):37-46

[3] Barlow DH, Durand VM. Abnormal psychology: An integrative approach. Canada: Wadsworth Group; 2002.

[4] American Psychiatric Association. Diagnostic and statistical manual of mental disorders. Washington D.C.: American Psychiatric Association; 2013.

[5] Lieb K, Vollm B, Rucker G, Timmer A, Stoffers J. Pharmacotherapy for Borderline Personality Disorder: Cochrane systematic rerview of randomised trials. The British Journal of Psychiatry. 2005; 196(1):4 12. [DOI:10.1192/bjp.bp.108.062984] [PMID]

[6] Mahmoudalilou M, Sharifi MA. [Borderline Personality Disorder theoretical topics and therapies (Persian)]. Tehran: Arjmand; 2014.

[7] Dziegielewski S. DSM-IV-TR in action. Hoboken: John Wily \& Sons; 2010

[8] Ghahari SH. Dialectical behavior therapy skills. Tehran: Ghatreh; 2015.

[9] Ghasemzade Nassaji S, Peyvastegar M, Hosseinian S, Mutabi F, Banihashemi S. [Effectiveness of cognitive-behavioral intervention on coping responses and cognitive emotion regulation strategies (Persian)]. Journal of Behavioral Sciences. 2010; 4(1):35-43

[10] Jana Abadi H, Zamani N. [Defense mechanisms in substance abusers' families (Persian)]. Journal of Research on Addiction. 2015 9(35):55-67.

[11] Yoselyani GH, Habibi M, Soleymani S. [The relationship between disciplines desired behavior and family functioning, locus of contro and self-esteem of students (Persian)]. Journal of School Psychology. 2012; 1(2):114-34.
[12] Sarno I, Madeddu F, Gratz K. Self-injury, psychiatric symptoms, and defense mechanisms: Findings in an Italian non-clinical sample. Journal of European Psychiatry. 2010; 25(3):136-45. [DOI:10.1016/j. eurpsy.2009.05.007] [PMID]

[13] Stern B, Yeomans F. The psychodynamic treatment of Borderline Personality Disorder. Journal of Psychiatric Clinic. 2018; 41(2):20723. [DOI:10.1016/j.psc.2018.01.012]

[14] Bond M. Empirical studies of defense style: Relationships with psychopathology and change. Journal of Harvard Review of Psychiatry. 2004; 12(5):263-78. [DOI:10.1080/10673220490886167] [PMID]

[15] Bond M, Perry J. Long-term changes in defense styles with psychodynamic psychotherapy for depressive, anxiety and personality disorders. American Journal of Psychiatry. 2004; 161(9):1665-71. [DOI:10.1176/appi.ajp.161.9.1665] [PMID]

[16] Paris J, Zweig Frank H. A 27-year follow-up of patients with Borderline Personality Disorder. Journal of Comprehensive Psychiatry. 2001; 42(6):482-7. [DOI:10.1053/comp.2001.26271] [PMID]

[17] Ferguson E. Personality and coping traits: A joint factor analysis. Journal of Health Psychology. 2001; 6(4):311-25. [DOI:10.1348/135910701169232] [PMID]

[18] Penley J, Tomaka J. Associations among the Big Five, emotiona responses, and coping with acute stress. Journal of Personality and Individual Differences. 2002; 32(17):1215-28. [DOI:10.1016/S0191 8869(01)00087-3

[19] Twamley E, Hami S, Stein M. Neuropsychological function in college students with and without posttraumatic stress disorder. Journal of Psychiatry Research. 2004; 126(3):265-74. [DOI:10.1016/j psychres.2004.01.008] [PMID]

[20] Mahmoudalilou M. Esmali A. Vahedi H. Rezaee R. [Investigate the relationship between personality characteristics (personality disorders) and problem solving styles in the offender prisoners (Persian)]. Journal of Daneshvar. 2009; 16(34):61-9.

[21] Ireland J, Brown S, Ballarini S. Maladaptive personality traits, coping styles and psychological distress: A study of adult male prisoners. Journal of Personality and Individual Differences. 2006; 41(3):561-73. [DOI:10.1016/j.paid.2006.03.002]

[22] Knafo A, Guilé JM, Breton JJ, Labelle R, Belloncle V, Bodeau N et al. Coping strategies associated with suicidal behaviour in adolescent inpatients with Borderline Personality Disorder. Canadian Journal of Psychiatry. 2015; 60(2 Suppl 1):S46-54. [PMCID] [PMID]

[23] Nower L, Derevensky J, Gupta R. The relationship of impulsivity, sensation seeking, coping, and substance use in youth gamblers. Journal of Psychology of Addictive Behaviors. 2004; 18(1):49-55. [DOI:10.1037/0893-164X.18.1.49] [PMID]

[24] Yen S, Gagnon K, Spirito A. Borderline Personality Disorder in suicidal adolescents. Journal of Personality and Mental Health. 2013 7(2):89-101. [DOI:10.1002/pmh.1216] [PMID] [PMCID]

[25] Lieb K, Zanarini MC, Schmahl C, Linehan MM, Bohus M. Borderline Personality Disorder. The Lancet. 2004; 364(9432):453-61 [DOI:10.1016/S0140-6736(04)16770-6]

[26] Rahmani F, Kiani M, Rezaie F, Nasuri M, Arasteh M. [Personality intellectual and emotional state of patients with Borderline Personality Disorder (Persian)]. Scientific Journal of Kurdistan University of Medical Sciences. 2013; 18(3):1-12

[27] Linehan M. Skills training manual for treating Borderline Personality Disorder. Tehran: Arjmand; 2015. 
[28] Porter C, Ireland C, Gardner C, Eslea M. Exploration of emotion regulation experiences associated with borderline personality features in a non-clinical sample. Journal of Borderline Personality Disorder and Emotion Dysregulation. 2016; 3(8):1-11. [DOI:10.1186/ s40479-016-0040-6]

[29] Mesgarian F, Azad Fallah P, Farahani H, Ghorbani N. [Object relations and defense mechanisms in social anxiety. Journal of Developmental Psychology: Iranian Psychologists (Persian)]. 2017; 14(53):3-14

[30] Besharat MA. [Alexithymia and defense styles (Persian)]. Journal of Fundamentals of Mental Health. 2009; 10(3):181-90.

[31] Besharat M. Relationship of alexithymia with coping styles and interpersonal problems. Journal of Procedia Social and Behavioral Sciences. 2010; 5:614-8. [DOI:10.1016/j.sbspro.2010.07.152]

[32] Besharata M, Shahidi S. What is the relationship between alexithymia and ego defense styles? A correlational study with Iranian students. Asian Journal of Psychiatry. 2011; 4(2):145-9. [DOI:10.1016/j. ajp.2011.05.011] [PMID]

[33] Besharat A, Mohammadi Hoseininezhad E, Gholamali Lavasani M. [The mediating role of cognitive emotion regulation strategies on the relationship between alexithymia, anger and anger rumination with ego defense styles (Persian)]. Journal of Contemporary Psychology. 2015; 9(2):29-48.

[34] Vaillant G. Adaptive mental mechanisms: Their role in a positive psychology. Journal of American Psychologist. 2000; 55(1):89-98. [DOI:10.1037/0003-066X.55.1.89]

[35] Kadivar P, Zahedi F . [The coping styles and suicide attempted among the female undergraduate students (Persian)]. Journal of Social Welfare Quarterly. 2007; 6(25):111-32.

[36] Bakhshipour Rodsari A, Mahmood Alilou M, Irani S. [The comparison of personality traits, personality disorders and problem-solving strategies in self-introduced addicts and normal population (Persian)]. Iranian Journal of Psychiatry and Clinical Psychology. 2008; 14(3):289-97.

[37] Aghdasi AN, Eydi R. [A study of the relationship between mental health and confronting procedures among the spinal cord (Persian)]. Journal of Instruction and Evaluation. 2011; 4(16):51-67.

[38] Mahmoudalilou M, Bakhshipour Roudsari A, Esmaeili M, Tofan Tabrizi M. [Personality traits and coping styles in subjects with major Hypotension (Persian)]. Medical Journal of Tabriz University of Medical Sciences. 2010; 32(2):61-6.

[39] Soltaninejad A, Fathi Ashtiani A, Ahmadi KH, Yahaghi E, Nikmorad $A$, Karimi R, et al. [Structural equation model of borderline personality disorder, emotion-focused coping styles, impulsivity and suicide ideation in soldiers (Persian)]. Journal of Police Medicine. 2013; 1(3):176-82.

[40] Kamali S, Hassani F. [Mental health and its relationship with stress coping strategies and emotional intelligence in female students at pre-university level (Persian)]. Journal of Behavioral Sciences. 2013; $7(1): 49-56$

[41] Vojoudi B, Hashemi T, Abdolpour G, Mashinchi Abbasi N. [Predicting suicide ideation based on identity styles and coping strategies (Persian)]. Journal of Contemporary Psychology. 2015; 10(19):47-56.

[42] Mazaheri MA, Borjali A, Ahadi H, Golshani F. [Effectiveness of dialectical behavior therapy in treatment of Borderline Personality Disorder (Persian)]. Psychological Research. 2010; 2(5):1-25.
[43] Levy K. The implications of attachment theory and research for understanding Borderline Personality Disorder. Journal of Development and Psychopathology. 2005; 17(4):959-86. [DOI:10.1017/ S0954579405050455]

[44] Andrews G, Singh M, Bond M. The Defense Style Questionnaire. Journal Nervous \& Mental Disease. 1993; 181(4):246-56. [DOI:10.1097/00005053-199304000-00006] 
This Page Intentionally Left Blank 